\title{
Catching up with wonderful women: The women-are-wonderful effect is smaller in more gender egalitarian societies
}

\author{
Kuba Krys ${ }^{1}$, Colin A. Capaldi ${ }^{2}$, Wijnand van Tilburg ${ }^{3}$, Ottmar V. Lipp ${ }^{4}$, \\ Michael Harris Bond ${ }^{5}$, C.-Melanie Vauclair 6 , L. Sam S. Manickam ${ }^{7}$, \\ Alejandra Domínguez-Espinosa ${ }^{8}$, Claudio Torres ${ }^{9}$, Vivian Miu-Chi Lun ${ }^{10}$, \\ Julien Teyssier ${ }^{11}$, Lynden K. Miles ${ }^{12}$, Karolina Hansen ${ }^{13}$, Joonha Park ${ }^{14}$, \\ Wolfgang Wagner ${ }^{15}$, Angela Arriola Yu ${ }^{16}$, Cai Xing ${ }^{17}$, Ryan Wise ${ }^{18}$, \\ Chien-Ru Sun ${ }^{19}$, Razi Sultan Siddiqui 20 , Radwa Salem ${ }^{21}$, Muhammad Rizwan ${ }^{22}$, \\ Vassilis Pavlopoulos ${ }^{23}$, Martin Nader ${ }^{24}$, Fridanna Maricchiolo ${ }^{25}$, María Malbran ${ }^{26}$, \\ Gwatirera Javangwe ${ }^{27}$, İdil Işık ${ }^{18}$, David O. Igbokwe ${ }^{28}$, Taekyun Hur $^{29}$, \\ Arif Hassan $^{30}$, Ana Gonzalez ${ }^{2}$, Márta Fülöp ${ }^{31}$, Patrick Denoux ${ }^{11}$, Enila Cenko ${ }^{32}$, \\ Ana Chkhaidze ${ }^{33}$, Eleonora Shmeleva ${ }^{34}$, Radka Antalíkováa ${ }^{35}$, \\ and Ramadan A. Ahmed ${ }^{36}$
}

\footnotetext{
${ }^{1}$ Institute of Psychology of Polish Academy of Sciences, Warsaw, Poland; ${ }^{2}$ Department of Psychology, Carleton University, Ottawa, Canada; ${ }^{3}$ Department of Psychology, King's College London, London, UK; ${ }^{4}$ School of Psychology and Speech Pathology, Curtin University, Perth, Australia; ${ }^{5}$ Department of Management and Marketing, Faculty of Business, Hong Kong Polytechnic University, Hong Kong; ${ }^{6}$ Instituto Universitário de Lisboa (ISCTE-IUL), Cis-IUL, Lisboa, Portugal; ${ }^{7}$ Centre for Applied Psychological Studies, JSS University, Kerala, India; ${ }^{8}$ Psychology Department, Iberoamerican University, Mexico City, Mexico; ${ }^{9}$ Institute of Psychology, University of Brasilia, Brazil; ${ }^{10}$ Department of Applied Psychology, Lingnan University, Hong Kong; ${ }^{11}$ Département Clinique du Sujet, Université Toulouse Jean Jaurès, Toulouse, France; ${ }^{12}$ School of Psychology, University of Aberdeen, Aberdeen, UK; ${ }^{13}$ Faculty of Psychology, University of Warsaw, Warsaw, Poland; ${ }^{14}$ Department of Management, Nagoya University of Commerce and Business, Nisshin, Japan; ${ }^{15}$ Department of Social and Economic Psychology, Johannes Kepler University, Linz, Austria; ${ }^{16}$ Department of Psychology, University of the Philippines-Diliman, Philippines; ${ }^{17}$ Department of Psychology, Renmin University of China, China; ${ }^{18}$ Department of Psychology, Istanbul Bilgi University, Istanbul, Turkey; ${ }^{19}$ Department of Psychology, National Chengchi University, Taiwan; ${ }^{20}$ Department of Management Sciences, DHA SUFFA University, Karachi, Pakistan; ${ }^{21}$ Silver School of Social Work, New York University, New York, NY, USA; ${ }^{22}$ Institute of Clinical Psychology, University of Karachi, Karachi, Pakistan; ${ }^{23}$ Department of Psychology, National and Kapodistrian University of Athens, Athens, Greece; ${ }^{24}$ Department of Psychological Studies, Universidad ICESI, Colombia; ${ }^{25}$ Department of Education, University of Roma Tre, Rome, Italy; ${ }^{26}$ Facultad de Humanidades y Ciencias de la Educación, Universidad Nacional de La Plata, Argentina; ${ }^{27}$ Department of Psychology, University of Zimbabwe, Harare, Zimbabwe; ${ }^{28}$ College of Leadership Development Studies, Covenant University, Ota, Nigeria; ${ }^{29}$ Department of Psychology, Korea University, Seoul, Republic of Korea; ${ }^{30}$ Department of Business Administration, International Islamic University Malaysia, Kuala Lumpur, Malaysia; ${ }^{31}$ Institute for Cognitive Neuroscience and Psychology, Hungarian Academy of Sciences, Hungary and Institute of Psychology, Eötvös Loránd University, Hungary; ${ }^{32}$ Social Sciences Research Center, University of New York Tirana, Tirana, Albania; ${ }^{33}$ Institute of Cognitive Neuroscience, Agricultural University of Georgia, Georgia; ${ }^{34}$ Graduate School of Management, St. Petersburg State University, Saint-Petersburg, Russia; ${ }^{35}$ Department of Communication and Psychology, Aalborg University, Denmark; ${ }^{36}$ Faculty of Arts, Menoufia University, Egypt
}

\footnotetext{
Correspondence should be addressed to Kuba Krys, Institute of Psychology of Polish Academy of Sciences, Jaracza 1, 00-378 Warsaw, Poland. (E-mail: kuba@krys.pl)

Research was supported by the Polish National Science Centre grant 2011/03/N/HS6/05112 (K.K.), National Natural Science Foundation of China grant 31200788 (C.X) and National Research, Development and Innovation Office grant no. OTKA-K-111 789 grant (M.F.).
} 
nequalities between men and women are common and well-documented. Objective indexes show that men are better
positioned than women in societal hierarchies - there is no single country in the world without a gender gap. In
contrast, researchers have found that the women-are-wonderful effect-that women are evaluated more positively than
men overall-is also common. Cross-cultural studies on gender equality reveal that the more gender egalitarian the society
is, the less prevalent explicit gender stereotypes are. Yet, because self-reported gender stereotypes may differ from implicit
attitudes towards each gender, we reanalysed data collected across 44 cultures, and (a) confirmed that societal gender
egalitarianism reduces the women-are-wonderful effect when it is measured more implicitly (i.e. rating the personality of
men and women presented in images) and (b) documented that the social perception of men benefits more from gender
egalitarianism than that of women.

Keywords: Culture; Social cognition; Gender egalitarianism; Gender stereotypes; Implicit attitudes.

Although evidence of gender equality within hunter-gatherer tribes suggests that gender egalitarianism might have been common throughout our species' evolutionary history (Dyble et al., 2015), it seems that men are structurally better positioned than women in modern societies; there is no single country in the world without a gender gap (World Economic Forum, 2014). On the other hand, researchers who study the women-are-wonderful effect (Eagly \& Mladinic, 1994; Williams \& Best, 1990) - that women are evaluated more positively than men overall-have shown that this effect is also ubiquitous across cultures (Glick et al., 2004). Yet, how objective gender (in)equality in a culture might influence the explicit and implicit social perception of gender is an understudied, but important, question. The present research aimed to address this gap by testing how the women-are-wonderful effect relates to cultural variations in gender equality.

Cuddy et al. (2015) showed that culture moderates the content of gender stereotypes and that stereotypes of men are more closely linked to core cultural values than are stereotypes of women. Cuddy et al. documented this phenomenon by reanalysing gender stereotype data from 26 cultures reported by Williams and Best (1990). They revealed that (a) the more collectivistic a culture is, the more collectivistic traits are stereotyped as masculine, and contrastingly that (b) the more individualistic a culture is, the more individualistic traits are stereotyped as masculine. Thus, Cuddy et al. confirm that cultures shape social perception of genders.

In two other multi-nation studies on gender stereotypes, Glick et al. (2004) found that societies' gender egalitarianism negatively correlates with both hostile and benevolent attitudes toward both men and women (Glick et al., 2000, 2004). They pointed out that as sexist ideologies maintain and reflect societal gender inequality, objective national indicators of gender inequality correspond with higher sexism. Glick et al. (2004) additionally asked participants in eight cultures to generate personality traits they associated with men and women, and to rate the positivity of these traits. This way they documented that both sexes evaluate women more positively than men, and confirmed that the women-are-wonderful effect (Eagly \& Mladinic, 1994) is ubiquitous across cultures. In another study, Glick and Fiske (2001) summarised that the women-are-wonderful effect functions to maintain male dominance and the gender status quo. However, Glick et al. did not relate the strength of the women-are-wonderful effect to objective gender (in)equality measures.

Both Cuddy et al. (2015) and Glick et al. (2000, 2004) activated gender stereotypes by explicitly asking about the roles or traits of men and women. Here we test whether the moderating role of culture is not only present when gender stereotypes are activated and explicitly measured, but also in more automatic and implicit social perception processes (i.e. when beliefs about genders are not measured explicitly, but indirectly through personality evaluations based on faces). Implicit gender stereotypes may differ from self-reported stereotypes because people may be unaware of the implicit stereotypes, they may not explicitly endorse them, or they do not wish to reveal that they endorse them (Nosek et al., 2009). Furthermore, some researchers claim (e.g. Anderson, 2014) that women in more gender egalitarian societies probably do not benefit from the women-are-wonderful effect. We therefore tested whether increased gender egalitarianism relates to more positive implicit attitudes towards men, and less so towards women. By supplementing the knowledge about explicit gender stereotypes with knowledge about more implicit attitudes towards men and women, we can better understand the way gender (in)equality in a given society affects the social perception of gender.

\section{METHOD}

To provide a systematic analysis of the implicit social perception of men and women across cultures, we reanalysed data collected by Krys et al. (2014, 2015, 2016), who asked participants in 44 cultures to rate photos of smiling and non-smiling male and female individuals on traits assessing honesty and intelligence. All target individuals in the photos were presented without any additional information. Furthermore, researchers did not explicitly 
activate the category of gender by openly asking about judgments of men and/or women. We expected to find an overall women-are-wonderful effect, which we operationalised as more positive evaluations of women in comparison to men.

\section{Participants and selection of cultures}

Post-secondary students from various fields were recruited at each author's university. Data were gathered from 5216 respondents in 44 cultures between 2011 and 2015. After removing individuals with missing answers on the dependent measures, the final sample consisted of 4519 participants. Demographic characteristics for all national samples are presented in Table S1 (Supporting Information).

The authors managed to collect data in 42 out of the 62 cultures involved in the GLOBE project (House, Hanges, Javidan, Dorfman, \& Gupta, 2004), and in Norway and Pakistan. We aimed to collect data from at least 120 individuals in each culture sampled (in some cultures, however, we collected more and in some other cultures we collected fewer; range: $48-300$ ).

\section{Materials and procedure}

The questionnaire started with the following instructions: "Research shows that people can quite accurately evaluate others based on their looks. Can you help us and rate some faces?" Participants rated the faces of four men and four women that were balanced for smiling vs. non-smiling and represented different ethnicities (the same number of male and female faces were shown for each ethnicity; for photos see Figure S1, Supporting Information) on a Likert-type scale ( $1=$ trait doesn't fit at all to $7=$ trait fits perfectly) on eight items (intelligent, dumb, smart, stupid, honest, false, authentic and unnatu$\mathrm{ral} ; \alpha=.89$ ). For each participant, we calculated the "general impression" of each target individual by averaging the ratings given for them across all eight items, with negative items reversed. The difference in general impression between ratings of women and men was used to test the women-are-wonderful effect. Photographs of the same persons posing neutral and smiling expressions were taken from the Center for Vital Longevity Face Database (Minear \& Park, 2004) and were organised into two sets, with targets who were smiling in one set presented as non-smiling in the other. The order of the photographs was randomized. Half of the participants received one set; the other half received the other set (see Figure S1).

In most cultures, the questionnaires also included items tracking self-esteem, motivation to control prejudiced reactions, and three additional attributes (i.e. attractiveness, friendliness and familiarity). At the end of the questionnaire all participants were asked to provide demographic information on their gender, age, student status and father's highest degree. Individuals were also asked about their religion, ethnicity and nationality in cultures where asking about this information was not problematic. Materials were prepared in Polish and English, and then translated from English into the language of every country covered by the study. In order to establish linguistic equivalence, team leaders were asked to follow the back-translation procedure.

As the main goal of the original study was related to the social perception of smiling and non-smiling individuals, the photos were of men and women smiling or not smiling, and therefore the smile factor needed to be controlled for in statistical analyses. Furthermore, in order to reliably identify cultural factors that are related to the differential social perception of men and women, we decided to employ multi-level modelling (MLM). A composite measure of gender egalitarianism $(\alpha=.84)$ was created based on GLOBE's gender egalitarianism practices (House et al., 2004), Hofstede's (2001) masculinity, Global Gender Gap (World Economic Forum, 2014), Gender Inequality Index (UNDP, 2014a), Gender-related Development Index (UNDP, 2014b) and the gender equality items from the World Values Survey (2014; see seven items presented in Appendix S1, Supporting Information). We did this by standardizing all six measures, reverse scoring some so that higher scores reflected greater gender egalitarianism, and calculating the average for every analysed country. In Table S1, we present cultural gender equality meta-factor statistics, as well as general impressions for target women and men in all national samples.

\section{RESULTS}

As predicted, we found an overall women-are-wonderful effect when all data were analysed together $\left(M_{\text {male }}=4.59\right.$, $S D_{\mathrm{m}}=.63, M_{\text {female }}=4.69, S D_{\mathrm{f}}=.64, t[4518]=11.0$, $p<.001, d=.16)$. In general, women were judged slightly more favourably than men. However, we expected to find cultural variability in the strength of this effect, and employed MLM in order to test our hypotheses regarding the relation of gender egalitarianism and the size of the women-are-wonderful effect. Analyses carried out on the gender egalitarianism meta-factor (extracted from six indexes) revealed a significant cross-level interaction between gender egalitarianism and target gender. None of the three-way interactions or four-way interactions were significant. For details of the MLM analysis, and for a full list of the two-way interactions, see Table S2.

Unpacking the cross-level two-way interaction revealed a negative correlation between the size of the women-are-wonderful effect and gender egalitarianism, $r(42)=-.50, p=.001$, suggesting that differences in the social perception of men and women are smaller 


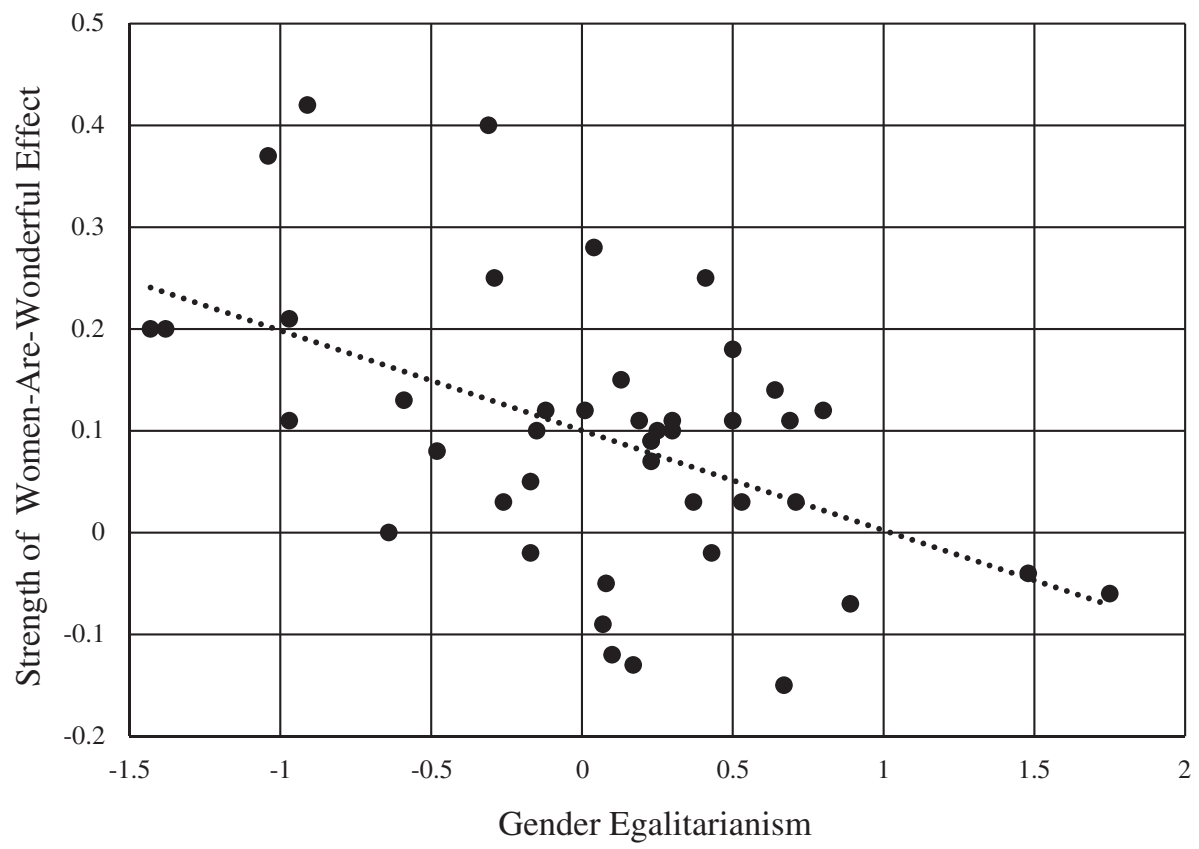

Figure 1. The relation between cultural gender egalitarianism and the strength of the women-are-wonderful effect (positive units on $y$-axis represent women being evaluated more positively than men).

in more gender egalitarian societies. We analysed the strength of the women-are-wonderful effect in the ten most and the ten least gender egalitarian societies of our sample to more clearly illustrate this finding. In the least egalitarian societies, men were perceived significantly less favourably than women $\left(M_{\text {male }}=4.41, S D_{\mathrm{m}}=.59\right.$, $M_{\text {female }}=4.60, \quad S D_{\mathrm{m}}=.61, \quad t[1187]=10.2, \quad p<.001$, $d=.32$ ), whereas for the top ten egalitarian societies the gender gap in general impression was only marginally significant $\left(M_{\text {male }}=4.74, S D_{\mathrm{m}}=.66, \quad M_{\text {female }}=4.78\right.$, $\left.S D_{\mathrm{m}}=.65, t[1050]=1.92, p=.055, d=.05\right)$. We also present the strength of women-are-wonderful effect in relation to gender egalitarianism in Figure 1.

Further unpacking of the two-way interaction revealed that gender egalitarianism is related to more positive general impressions about men, $r(42)=.54, p<.001$, and almost marginally significantly related to general impressions about women, $r(42)=.25, p=.105$ (the difference between these two correlations was marginally significant, $z=1.60, p=.055)$. This means that increased cultural gender egalitarianism is more strongly related to general impressions about men than women.

\section{DISCUSSION}

Previous cross-cultural studies on sexism (Glick et al., 2000, 2004) explicitly activated gender stereotypes and showed that the women-are-wonderful effect is ubiquitous across cultures (Glick et al., 2004). We reanalysed data collected in 44 cultures by Krys et al. (2016) and found that the women-are-wonderful effect, when measured indirectly (i.e. when participants do not explicitly express their beliefs about each gender), is smaller in societies that are more gender-egalitarian. Thus, we extended the knowledge about gender stereotyping and documented that the moderating role of a culture's level of gender egalitarianism on perception of men and women is present not only in explicitly measured attitudes towards each gender, but also in more implicit social perception of men and women.

Furthermore, we delivered the first broad, crosscultural support for Anderson's (2014) proposition that women may benefit from gender egalitarianism less than men do when it comes to social perception. In our study, positive attitudes towards women were not significantly related to gender egalitarianism, whereas attitudes towards men were positively related to gender equality. Indeed, the positive relationship between gender egalitarianism and attitudes towards men was stronger than the same relationship for women. To explain this result, we turn to the cultural moderation of gender stereotypes hypothesis of Cuddy et al. (2015), who documented that stereotypes of men more closely align with core cultural values - in our study gender egalitarianism - than do stereotypes of women, though further studies are needed to more comprehensively identify the underlying mechanisms.

Although the large number of cultures sampled strengthens the presented conclusions, our study has some shortcomings. For instance, the lack of negative facial expressions (e.g. sad, angry or scared faces) in 
the stimuli we used is one weakness. Another limitation of the presented research lies in the lack of context when making judgments; contextual information may differentially influence perceptions of men relative to women (Eagly \& Karau, 2002). Also, perceiver ethnicity should be analysed in future studies as ingroup and outgroup effects may play a role in these social perception processes. Next, following Krys et al. (2016) we used the term culture, although the group-level distinctions could have alternatively been labelled national culture or just nation (excluding South Africa and India as they were explicitly split into cultural sub-samples). We are aware that culture is a far more complex construct than nation; future studies need to be more precise in differentiating these two. Further, additional variables, such as attractiveness, need to be better controlled. Lastly, future studies should try to recruit samples that are more representative of the cultures they come from as participants in the current study were all students.

Although the women-are-wonderful effect presumes that women are perceived more favourably than men, our study suggests that, at the cultural-level, the direction of this comparison may be the opposite: perceptions of men are relatively worse compared to women in societies low in gender equality. Therefore, we suggest that the women-are-wonderful effect may, at the level of cultures, be redefined as the "men-are-minimized" effect for societies with greater gender inequality.

Most previous studies on the benefits of gender egalitarianism have focused on women. Men's advantages from gender egalitarianism were documented on rare occasions, and quite often were limited to minimising negative effects of gender inequality (i.e. lower levels of militarism, alcoholism or violence among men living in more gender egalitarian societies; Barker et al., 2011). Holter (2014) described an "emerging culture of gender equality," which he associated with improved health and well-being, lower violence and less strict hegemonic masculinity. The benefits of less aversive behaviour by men accrue to the more positive stereotype they earn. By showing that the social perception of men is improved in societies that are higher in gender egalitarianism, our study contributes to the discussion about how gender equality is not only a women's issue, but a men's issue as well.

Manuscript received July 2016 Revised manuscript accepted February 2017 First published online March 2017

\section{SUPPORTING INFORMATION}

Additional supporting information may be found online in the Supporting Information section at the end of the article.

Table S1. Samples' characteristics.

Table S2. Unstandardised coefficients from multilevel linear regression analyses of judgements of a target person.
Figure S1. Photographs used in the Krys et al. (2016) study. Participants assessed either the faces in the upper or those in the lower row.

\section{REFERENCES}

Anderson, K. (2014). Modern misogyny: Anti-feminism in a post-feminist era. Oxford, U.K.: Oxford University Press.

Barker, G., Contreras, J., Heilman, B., Nascimento, M., Singh, A., \& Verma, R. (2011). Evolving men: Initial results from the International Men and Gender Equality Survey (IMAGES). Washington, DC: ICRW.

Cuddy, A., Wolf, E., Glick, P., Crotty, S., Chong, J., \& Norton, M. (2015). Men as cultural ideals: Cultural values moderate gender stereotype content. Journal of Personality and Social Psychology, 109, 622-635. doi:10.1037/pspi0000027.

Dyble, M., Salali, G. D., Chaudhary, N., Page, A., Smith, D., Thompson, J., ... Migliano, A. B. (2015). Sex equality can explain the unique social structure of hunter-gatherer bands. Science, 348, 796-798. doi:10.1126/science.aaa5139.

Eagly, A., \& Karau, S. (2002). Role congruity theory of prejudice toward female leaders. Psychological Review, 109, 573-598. doi:10.1037//0033-295X.109.3.573.

Eagly, A., \& Mladinic, A. (1994). Are people prejudiced against women? Some answers from research on attitudes, gender stereotypes, and judgments of competence. European Review of Social Psychology, 5, 1-35. doi:10.1080/14792779543000002.

Glick, P., \& Fiske, S. (2001). An ambivalent alliance: Hostile and benevolent sexism as complementary justifications for gender inequality. American Psychologist, 56, 109-118. doi:10.1037/0003-066X.56.2.109

Glick, P., Fiske, S., Mladinic, A., Saiz, J., Abrams, D., Masser, B., ... Lopez, W. (2000). Beyond prejudice as simple antipathy: Hostile and benevolent sexism across cultures. Journal of Personality and Social Psychology, 79, 763-775. doi:10.1037/0022-3514.79.5.763.

Glick, P., Lameiras, M., Fiske, S., Eckes, T., Masser, B., Volpato, C., ... Wells, R. (2004). Bad but bold: Ambivalent attitudes toward men predict gender inequality in 16 nations. Journal of Personality and Social Psychology, 86, 713-728. doi:10.1037/0022-3514.86.5.713.

Hofstede, G. (2001). Culture's consequences: Comparing values, behaviors, institutions and organizations across nations. Thousand Oaks, CA: Sage.

Holter, O. (2014). "What's in it for men?": Old question, new data. Men and Masculinities, 17, 515-548. doi:10.1177/1097184X14558237.

House, R., Hanges, P., Javidan, M., Dorfman, P., \& Gupta, V. (2004). Culture, leadership, and organizations: The GLOBE study of 62 societies. Thousand Oaks, CA: Sage.

Krys, K., Hansen, K., Xing, C., Espinoza, A., Szarota, P., \& Morales, M. (2015). It is better to smile to women: Gender modifies perception of honesty of smiling individuals across cultures. International Journal of Psychology, 50, 150-154. doi:10.1002/ijop.12087. 
Krys, K., Hansen, K., Xing, C., Szarota, P., \& Yang, M. (2014). Do only fools smile at strangers? Cultural differences in social perception of intelligence of smiling individuals. Journal of Cross-Cultural Psychology, 45, 314-321. doi:10.1177/0022022113513922.

Krys, K., Vauclair, M., Capaldi, C., Lun, V. M.-C., Bond, M. H., Domínguez-Espinosa, A., ... Yu, A. (2016). Be careful where you smile: Culture shapes judgments of intelligence and honesty of smiling individuals. Journal of Nonverbal Behavior, 40, 101-116. doi:10.1007/s10919-015-0226-4.

Minear, M., \& Park, D. (2004). A lifespan database of adult facial stimuli. Behavior Research Methods, Instruments, \& Computers, 36, 630-633. doi:10.3758/ BF03206543.

Nosek, B., Smyth, F., Sriram, N., Lindner, N., Devos, T., Ayala, A., ... Greenwald, A. (2009). National differences in gender-science stereotypes predict national sex differences in science and math achievement. Proceedings of the National Academy of Sciences of the United States of America, 106, 10593-10597. doi:10.1073pnas.0809921106.

UNDP. (2014a). Gender Inequality Index. Retrieved from http:// hdr.undp.org/en/composite/GII

UNDP. (2014b). Gender Development Index. Retrieved from http://hdr.undp.org/en/composite/GDI

Williams, J., \& Best, D. (1990). Measuring sex stereotypes: A multinational study. Beverly Hills, CA: Sage.

World Economic Forum. (2014). The Global Gender Gap Index 2014. Retrieved from http://reports.weforum.org/globalgender-gap-report-2014/ 